\title{
SITUACIÓN DO MEDIO TELEVISIVO EN GALICIA (2012-2014): CONTEXTO, AUDIENCIA, INVESTIMENTO PUBLICITARIO, USO DO GALEGO E TENDENCIASS
}

Silvia García Mirón

Mónica Valderrama Santomé Universidade de Vigo

Doi:10.17075/aceg.2016.004 



\section{PRESENTACIÓN}

Tras varios anos de transformación do modelo televisivo no contexto español mediante a integración do sistema dixital e das novas fórmulas de distribución e promoción de contidos televisivos a través de Internet así como dun reaxuste do mercado, no ano 2012 observouse un forte incremento do consumo televisivo no país (non tanto na comunidade autónoma galega) xunto ao inicio da concentración do sector, que será máis significativa en 2013, ata que se advertirá a recuperación do investimento publicitario - despois de anos de recesión- no ano 2014. Estes tres últimos anos tamén posuirán como principal evento a debilitación da televisión pública, especialmente polo peche de Canal Nou na Comunidade Valenciana en 2013, que se produciu sen que realmente fosen medidas as consecuencias da decisión e que trasladou ao resto de comunidades así como ao panorama nacional as dúbidas sobre o mantemento das emisoras públicas. Este feito, xunto ao fin de 9 canles dixitais, debuxou un novo mapa do sector no bienio 2012-2014, con características diferenciais con respecto a anos previos.

\section{OBXECTO DE ESTUDO E METODOLOXÍA}

O presente texto céntrase en realizar unha análise da actual situación do medio televisivo entre 2012 e 2014 en Galicia, especialmente no tocante a varios ítems de estudo: en primeiro lugar, atendendo aos principais fitos que tiveron lugar en relación con este medio de comunicación; en segundo lugar, a evolución do seu consumo na comunidade así como a audiencia das emisoras autonómicas galegas; en terceiro lugar, ofrecendo os datos máis significativos arredor do investimento publicitario no medio; e, por último, uns apuntamentos sobre o uso do galego por parte das emisoras protagonistas do medio en Galicia.

Para coñecer estes parámetros teremos en conta a oferta da televisión na comunidade galega en termos de cobertura en aberto e de forma gratuíta. Por tanto, observaremos a presenza e comportamento das emisoras autonómicas, tanto públicas (TVG e TVG2) como privadas (V Televisión), así como aquelas de carácter local.

O deseño metodolóxico da investigación, de carácter esencialmente descritivo, configúrase mediante unha fórmula mixta na que se empregan principalmente datos cuantitativos (especialmente os referidos á información do consumo e audiencia televisiva e investimento publicitario ou, mesmo, dos principais xéneros incluídos na programación das emisoras galegas) e tamén outros cualitativos, como aqueles empregados á hora de conseguir información relativa ao actual contexto do medio televisivo en Galicia así coma ao uso da lingua galega por parte das emisoras que operan na comunidade.

\section{CONTEXTO E ANTECEDENTES}

O medio televisivo atópase inmerso nunha revolución que comprende varias perspectivas: a primeira delas de carácter tecnolóxico, a segunda en termos creativos e, por último, dende a revolución do espectador e os cambios no seu 
comportamento ${ }^{1}$. Non obstante, entre todo isto destaca como factor clave que o contido seguirá sendo o elemento diferenciador e motor da industria. Ante os cambios no consumo, o certo é que os contidos televisivos continúan consumíndose en gran medida dende a pantalla tradicional do televisor por parte do espectador máis conservador e pasivo en ocasións; pero vai gañando terreo nos últimos anos o consumo a través das segundas ou terceiras pantallas (ordenadores e dispositivos móbiles) que permiten distintas opcións de visionado (directo, streaming, descarga, etc.) e vénse favorecendo a incorporación de distintas posibilidades de interacción (redes sociais, creación de experiencias transmedia, etc.) empregadas por parte dun usuario máis dinámico, proactivo, ambicioso e devorador de contidos audiovisuais pero, ao mesmo tempo, máis individualista no seu consumo (Barlovento Comunicación 2014).

Á parte desta revolución, no contexto español obsérvanse outros aspectos que condicionan a situación do medio na comunidade galega, sendo o máis influente o económico. A crise económica iniciada no ano 2008 supuxo que os gobernos autonómicos reconsiderasen a importancia do mantemento das emisoras públicas. O seu cuestionamento non reside na súa función, finalidade ou vocación de servizo público, senón no seu custo. Durante este período, as autonómicas están inmersas nun contexto de máxima austeridade e de busca de alternativas para o seu posicionamento no mercado. Porén, polo de agora, desmentiuse calquera idea neste senso por parte da Administración autonómica galega ${ }^{2}$ a pesar de que os datos que amosan os orzamentos da TVG indicaban ata o 2014 esta tendencia, que se rompeu cos orzamentos para o ano $2015^{3}$ cun lixeiro aumento nas achegas por parte da Xunta (cfr. táboa 1). Por outra banda, advertimos que esta inestabilidade dos últimos anos comportou que en 2014 a cota de pantalla das autonómicas rexistrase un mínimo histórico anual (8,0%) (Barlovento Comunicación 2014).

Táboa 1. Evolución do orzamento da TVG

\begin{tabular}{lccc} 
Ano & Orzamento (millóns $€$ ) & Achegas Xunta & Investimento publicitario \\
\hline 2012 & 117,1 & $100,8 \mathrm{~m} €$ & $13,9 \mathrm{~m} €$ \\
\hline 2013 & 103,7 & $93,7 \mathrm{~m} €$ & $10 \mathrm{~m} €$ \\
\hline 2014 & 99,4 & $90 \mathrm{~m} €$ & $9,4 \mathrm{~m} €$ \\
\hline 2015 & 106,8 & $95,8 \mathrm{~m} €$ & $11 \mathrm{~m} €$ \\
\hline
\end{tabular}

Fonte: elaboración propia a partir dos informes corporativos da CRTVG.

Por outra banda, atopámonos nun contexto variable en relación cos propios protagonistas que operan no medio. Deste xeito, no ano 2014 facíase efectiva por parte do Ministerio de Industria a sentenza do Tribunal Supremo que obrigaba ao peche de 9 canles, polo que deixaron de emitir Nitro, Xplora, La Sexta 3, La Siete, Nueve, Intereconomía, MTV, AXN e Teletienda (antiga Marca TV). Este feito xunto ao proceso de fusións (A3-La Sexta e T5-Cuatro) que comporta a creación dun mercado atomizado arredor de tres grupos principais de comunicación no medio (Mediaset, Atresmedia e RTVE) crean a silueta deste novo mapa.

\footnotetext{
${ }^{1}$ Cfr. Entrevista a Paloma Bravo, directora de Márketing e Publicidade da área de vídeo de Telefónica, en «19 expertos nos cuentan como será la televisión del futuro», en http://toyoutome.es/blog/19-expertos-nos-cuentan-como-sera-la-television-del-futuro/35198 (23/03/2015).

2 «Feijóo descarta el cierre de TVG porque tiene unas cuentas saneadas» (6 de novembro de 2013), El País, na súa edición dixital http://ccaa.elpais.com/ccaa/2013/11/06/galicia/1383744888_087180.html (20/02/2015).

3 Tras ter unhas débedas acumuladas dos últimos anos e no seu proceso de conversión nunha corporación, a CRTVG pecharía o ano 2013 con superávit de 0,3 millóns de euros. Cfr. «La CRTVG cerró 2013 con superávit de 0,3 millóns de euros» (30/05/2014), Europa Press, na súa edición online http://www.europapress.es/galicia/noticia-crtvg-cerro-2013-superavit-03-millones-redujo-cero-endeudamiento-bancario-32-millones-2009-20140530144011.html (15/03/2015).
} 
Poñendo o foco no contexto televisivo galego, o actual escenario está protagonizado por dúas canles públicas (TVG e TVG2), unha emisora privada con cobertura autonómica (V Televisión, operada polo Grupo Voz Audiovisual S.L.) e un conxunto de emisoras locais que amosamos na táboa 2.

Táboa 2. Listaxe de emisoras de carácter local en Galicia

\begin{tabular}{ll} 
A Coruña & Pontevedra \\
\hline Correo TV & Canal Rías Baixas \\
\hline Santiago TV & Canal Vía Televisión \\
\hline Eume TV & Correo TV \\
\hline TV Ferrol & Nós TV \\
\hline Canle explotada por Mancumunidade do Salnés & Canle explotada por Editorial La Capital \\
\hline Canle explotada por Editorial Compostelana & Canle explotada por Faro de Vigo \\
\hline Canle explotada por Editoral La Capital & Canle explotada por Lérez Canal 29 \\
\hline Canle explotada por Faro de Vigo & Canle explotada por Multimedia Comun. \\
\hline Canle explotada por La Opinión de La Coruña & Canle explotada por Rías Baixas Produc. \\
\hline Canle explotada por Multimedia Comunicaciones & Canle explotada por TV Pontevedra \\
\hline Canle explotada por Salitre Multimedia & Canle explotada por Utega \\
\hline Canle explotada por Utega & \\
\hline Lugo & Ourense \\
\hline Telelugo & Auria TV \\
\hline Telemiño & Telemiño \\
\hline Televinte & Canle explotada por Faro de Vigo \\
\hline Canle explotada por TV7 Monforte & \\
\hline Canle explotada por Alternativas de Medios Aud. & \\
\hline
\end{tabular}

Fonte: Anuario SGAE das Artes Escénicas, Musicais e Audiovisuais 2014.

Debemos sinalar, así mesmo, nesta epígrafe, que no período de estudo tamén se contaba cunha segunda emisora privada autonómica, Popular TV Galicia (promovida polo Grupo Cope), que resultou unha das dúas licenzas adxudicadas en 2005. Finalizaría as súas emisións o 31 de xullo de 2013 pola imposibilidade económica de manter o proxecto ante o limitado investimento publicitario.

Por último, tamén resulta de relevancia facer mención ao proceso de conversión da TVG en Corporación durante o ano 2014, mediante o que se fusionaron as tres organizacións que conviven na CRTVG coa finalidade de «reflectir sinerxías, aforro e eficiencia» ${ }^{4}$ e flexibilizar a súa xestión.

\section{SITUACIÓN}

Os anos 2012 e 2013 configúranse a nivel nacional como aqueles en que se alcanza o récord absoluto de consumo televisivo: 246 minutos por persoa e día en 2012 e 244 en 2013. Así e todo, Galicia sería nestes dous anos a co-

\footnotetext{
4 «A CRTVG afronta en 2014 a súa conversión en Corporación baixando o seu orzamento ata 99,4 millóns e sen débeda» (05/11/2013), na páxina web corporativa da CRTVG, http://www.crtvg.es/crtvg/crtvgviva/a-crtvg-afronta-en-2014-a-sua-conversion-en-corporacionbaixando-o-seu-orzamento-ata-99-4-millons-e-sen-debeda (25/03/2015).
} 
munidade autónoma española onde se produce o menor consumo de televisión, con 221 minutos, se ben consegue certo aumento no ano 2014 (228 minutos), tal e como se pode apreciar no gráfico 1.

Gráfico 1. Evolución do consumo televisivo por comunidades autónomas (2012-2014)

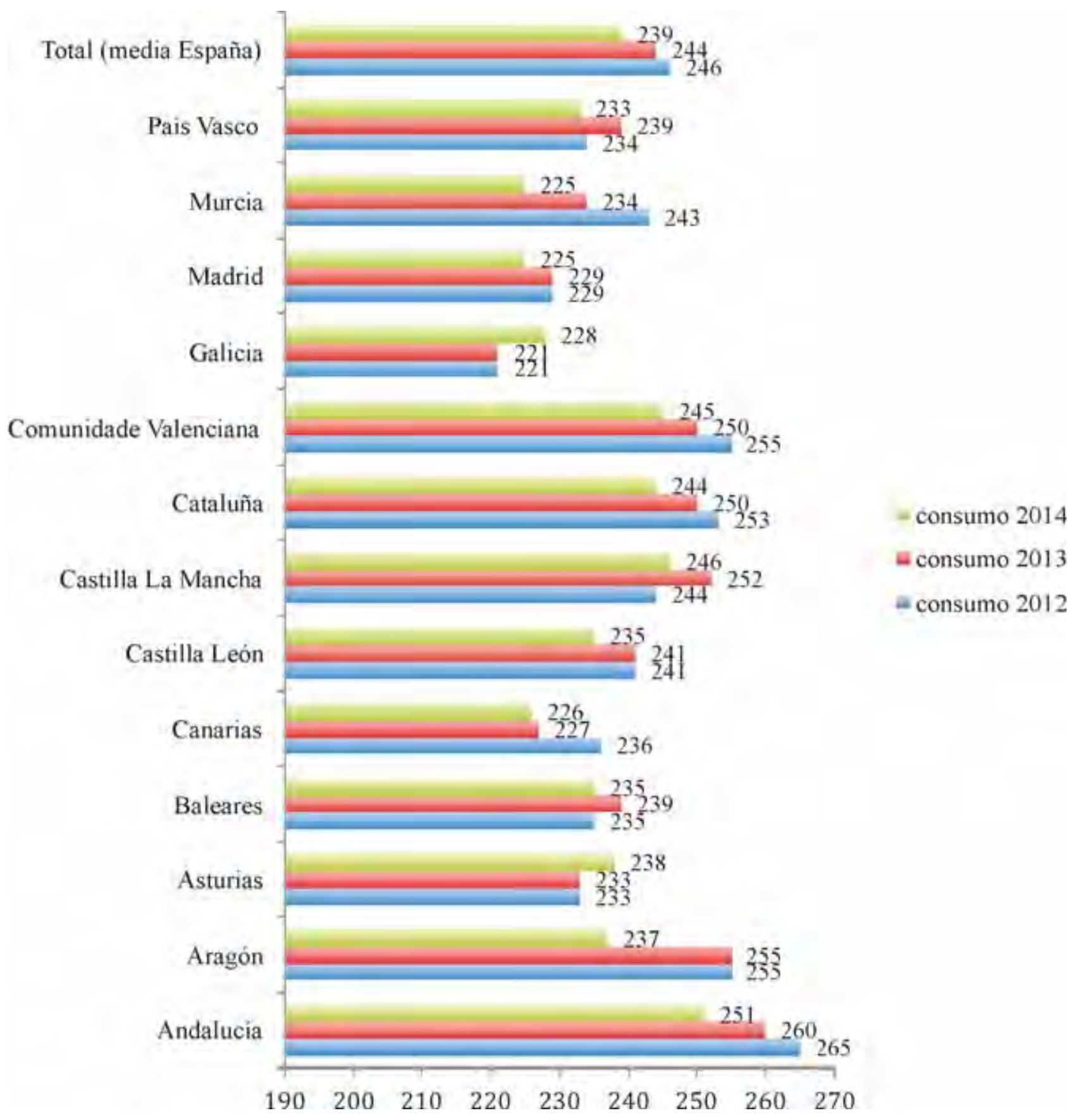

Fonte: elaboración propia a partir de datos de Kantar Media. 
Dende o 2012, a meirande parte das emisoras autonómicas veñen rexistrando mínimos anuais debido á fragmentación. A autonómica que consegue unha maior cota no ano 2012 foi TV3 (14,3 \%), seguida da TVG (11,5\%). Tanto os datos globais das emisoras autonómicas en España como os datos individuais de cada unha das canles que operan en Galicia (TVG, TVG2, V Televisión) amosan este descenso na súa cota de pantalla dende o ano 2011 (táboa 3). A excepción atopámola nas autonómicas privadas, que aumentan o seu consumo no ámbito nacional, cunha media do $0,9 \%$ en 2014.

Táboa 3. Evolución da cota de pantalla das emisoras autonómicas galegas

Emisora

\begin{tabular}{lrrrr} 
& $\mathbf{2 0 1 1}$ & $\mathbf{2 0 1 2}$ & $\mathbf{2 0 1 3}$ & $\mathbf{2 0 1 4}$ \\
\hline TVG & 12,3 & 11,5 & 10,9 & 10,0 \\
\hline TVG2 & 0,9 & 0,9 & 0,9 & 0,8 \\
\hline V Televisión & 0,6 & 0,6 & 0,4 & 0,4 \\
\hline Total autonómicas España & 10,4 & 9,8 & 8,7 & 8,0 \\
\hline Autonómicas privadas & 0,8 & 0,9 & 0,8 & 0,9 \\
\hline
\end{tabular}

Fonte: Barlovento Comunicación a partir de datos de Kantar Media.

Por último, polo que respecta ás televisións locais, os datos do ano 2013 amosan que en Galicia teñen unha audiencia do 12,3 \% (audiencia acumulada nos últimos 30 días segundo o Marco Xeral dos Medios en España, 2014), situándose nunha posición intermedia en relación co resto de comunidades españolas (A Rioxa, cun $44,7 \%$, e Canarias, cun 43,2 \%, serían as que conseguen unha maior presenza, mentres que as de Castela e León, cun 2,0 \%, ou Baleares, cun 2,9\%, son as que acadan os datos máis baixos).

Táboa 4. Perfil do espectador en Galicia e das emisoras públicas galegas

Total TV Galicia

TVG

TVG2

\section{SEXO}

\begin{tabular}{llll}
\hline Home & $47,9 \%$ & $40,8 \%$ & $54,9 \%$ \\
\hline Muller & $52,2 \%$ & $59,2 \%$ & $45,1 \%$
\end{tabular}

IDADE

\begin{tabular}{lrrr}
\hline De 4 a 9 & $1,7 \%$ & $1,0 \%$ & $2,4 \%$ \\
\hline De 10 a 15 & $2,0 \%$ & $0,6 \%$ & $3,3 \%$ \\
\hline De 16 a 19 & $1,2 \%$ & $0,7 \%$ & $1,7 \%$ \\
\hline De 20 a 24 & $2,2 \%$ & $1,9 \%$ & $2,4 \%$ \\
\hline De 25 a 34 & $9,2 \%$ & $7,1 \%$ & $11,2 \%$ \\
\hline De 35 a 44 & $13 \%$ & $9,1 \%$ & $16,8 \%$ \\
\hline De 45 a 54 & $15,3 \%$ & $13,6 \%$ & $16,9 \%$ \\
\hline De 55 a 64 & $17,9 \%$ & $20,3 \%$ & $15,4 \%$ \\
\hline De 65 ou máis & $37,8 \%$ & $45,7 \%$ & $29,9 \%$ \\
\hline CLASE SOCIAL & & & $18,6 \%$ \\
\hline Alta e media-alta & $14,8 \%$ & $10,9 \%$ & $42,6 \%$ \\
\hline Media & $41,8 \%$ & $40,9 \%$ & $38,9 \%$ \\
\hline Media-baixa e baixa & $43,6 \%$ & $48,2 \%$ &
\end{tabular}


Total TV Galicia

TVG

TVG2

\begin{tabular}{lrrr}
\hline HÁBITAT $\left(\mathbf{n}^{\circ}\right.$ hab.) & & & \\
\hline-10000 & $41,1 \%$ & $43,9 \%$ & $38,2 \%$ \\
\hline $10000-50000$ & $30,0 \%$ & $34,3 \%$ & $25,6 \%$ \\
\hline $50000-200000$ & $18,6 \%$ & $13,5 \%$ & $23,7 \%$ \\
\hline $200000-500000$ & $10,4 \%$ & $8,3 \%$ & $12,5 \%$ \\
\hline+500000 & - & - & - \\
\hline
\end{tabular}

Fonte: Anuario SGAE das Artes Escénicas, Musicais e Audiovisuais 2014.

Verbo do perfil do espectador en Galicia (táboa 4), os datos relativos ao ano 2013 indican que o público da televisión na comunidade galega é, en xeral, máis feminino, algo que se representa de igual modo na TVG. 0 espectador desta canle amósase como esencialmente maior, tendo en conta que o 66 \% responde á franxa de 55 anos ou máis e só un 4,9 \% teñen menos 20 anos; de clase baixa ou media-baixa e do ámbito rural. Pola contra, a TVG2 ten un perfil máis novo, máis masculino, de clase media e de ámbito máis urbano que o da TVG.

Táboa 5. Emisións máis vistas en Galicia no último mes (febreiro 2015)

\begin{tabular}{lllrl} 
Rk & Canle & Título & Aud.máx. & Cota \\
\hline 1 & Cuatro & Fútbol. Liga España: Deportivo-Celta & 14,8 & 21,1 \\
\hline 2 & La 1 & Fútbol. Champions League: Manch. City-Barcelona & 12,3 & 25,1 \\
\hline 3 & T5 & Informativos Telecinco 21.00 h & 11,3 & 20,6 \\
\hline 4 & T5 & GH VIP & 9,7 & 29,7 \\
\hline 5 & T5 & Pasapalabra & 9,6 & 25,0 \\
\hline $\mathbf{6}$ & TVG & Telexornal 1 14:30 h & $\mathbf{9 , 6}$ & $\mathbf{2 7 , 3}$ \\
\hline 7 & A3 & Bajo sospecha («El vestido») & 9,2 & 17,7 \\
\hline 8 & La Sexta & Salvados («A lo Espe») & 8,8 & 10,3 \\
\hline 9 & A3 & Velvet («La hora de la verdad») & 8,8 & 15,3 \\
\hline 10 & T5 & GH VIP: El debate & 8,5 & 23,6 \\
\hline 11 & T5 & Levántate Express & 8,4 & 17,6 \\
\hline 12 & T5 & Levántate & 8,4 & 21,4 \\
\hline $\mathbf{1 3}$ & TVG & Telexornal 1 15:00 h & $\mathbf{8 , 2}$ & $\mathbf{1 8 , 0}$ \\
\hline 14 & T5 & GH VIP: Última hora & 8,2 & 14,6 \\
\hline 15 & La 1 & Cuéntame como pasó («Polvo al polvo») & 8,1 & 17,5 \\
\hline 16 & T5 & Hay una cosa que te quiero decir: previo & 8,0 & 17,8 \\
\hline 17 & T5 & GH VIP: Expres & 7,7 & 16,0 \\
\hline $\mathbf{1 8}$ & TVG & Serramoura («Guerra: segunda parte») & $\mathbf{7 , 5}$ & $\mathbf{1 3 , 9}$ \\
\hline 19 & La 1 & Los Goya & 7,5 & 21,0 \\
\hline 20 & La Sexta & El intermedio & 7,3 & 12,9 \\
\hline & & & &
\end{tabular}

Fonte: Kantar Media.

No que atinxe á audiencia, tamén resulta preciso destacar as emisións máis vistas na comunidade galega (táboa 5) en función da audiencia máxima no último mes (febreiro de 2015). Neste ránking só se atopan 3 programas emitidos pola TVG: o Telexornal (en dúas ocasións) e un capítulo da ficción Serramoura. Se observamos os espazos 
coa maior audiencia media da TVG en 2014, acadan o ránking programas de entretemento familiar como Era visto!, Entre familias anda o xogo, Luar ou Larpeiros.

Táboa 6. Emisións más vistas da TVG (xullo-decembro 2014)

\begin{tabular}{|c|c|c|c|c|c|c|c|}
\hline Mes & Emisións & $\begin{array}{l}\text { Aud. } \\
\text { media }\end{array}$ & Share & Mes & Emisións & $\begin{array}{l}\text { Aud. } \\
\text { media }\end{array}$ & Share \\
\hline \multirow{5}{*}{ Xul } & Telexornal 114.30 & 8,3 & 31,0 & \multirow{5}{*}{ Out } & Telexornal 114.30 & 9,4 & 32,1 \\
\hline & Telexornal 115.00 & 6,7 & 23,0 & & Serramoura & 7,0 & 17,0 \\
\hline & Sopa de festa & 5,9 & 15,1 & & Telexornal 115.00 & 7,0 & 21,0 \\
\hline & Fogos do Apóstolo & 5,9 & 18,0 & & Casa Manola & 6,9 & 15,8 \\
\hline & Larpeiros & 5,7 & 16,2 & & Galicia Noticias & 6,4 & 27,2 \\
\hline \multirow{5}{*}{ Ago } & Telexornal 114.30 & 9,4 & 34,3 & \multirow{5}{*}{ Nov } & Telexornal 114.30 & 10,2 & 34,5 \\
\hline & Fútbol DEP.-CEL. & 7,7 & 22,7 & & Serramoura & 6,6 & 14,5 \\
\hline & Telexornal 115.00 & 5,9 & 22,6 & & Galicia Noticias & 6,6 & 30,1 \\
\hline & Galicia Noticias & 5,6 & 28,4 & & Telexornal 115.00 & 6,6 & 23,2 \\
\hline & Sopa de festa & 5,6 & 14,6 & & Telexornal 221.00 & 5,6 & 16,0 \\
\hline \multirow{5}{*}{ Set } & Telexornal 114.30 & 8,8 & 32,4 & \multirow{5}{*}{ Dec } & Telexornal 114.30 & 10,0 & 35,9 \\
\hline & Telexornal 115.00 & 6,9 & 25,2 & & Serramoura & 8,1 & 18,5 \\
\hline & Galicia Noticias & 6,3 & 30,4 & & Telexornal 115.00 & 7,3 & 24,9 \\
\hline & Telexornal 221.00 & 6,0 & 18,5 & & Telexornal 221.00 & 6,9 & 15,6 \\
\hline & Larpeiros & 5,7 & 13,3 & & Larpeiros & 6,7 & 14,5 \\
\hline
\end{tabular}

Fonte: Kantar Media.

En canto ao investimento publicitario, durante o bienio 2012-2014 advertiranse os resultados da crise económica e publicitaria mediante o descenso nas cifras de investimento publicitario na televisión (cun retroceso arredor do $18 \%$ no ano 2012 e outro $10 \%$ en 2013, pasa de 1850 millóns de euros, aproximadamente, a 1650). Tras varios anos de recesión (pola crise e tamén debido ao investimento derivado a outros soportes como Internet), o investimento no medio consegue recuperarse a partir de 2014 (táboa 7).

Táboa 7. Evolución dos ingresos publicitarios das emisoras autonómicas en España

\begin{tabular}{lrrrr} 
& \multicolumn{4}{c}{ Investimento publicitario (millóns de euros) } \\
\hline Emisora & $\mathbf{2 0 1 1}$ & $\mathbf{2 0 1 2}$ & $\mathbf{2 0 1 3}$ & $\mathbf{2 0 1 4}$ \\
\hline TVG/TVG2 (CRTVG) & 12,2 & 13,9 & 7,9 & 7,6 \\
\hline Total autonómicas España & 198,0 & 126,8 & 120,4 & 128,7 \\
\hline Total TV en España & 2237,2 & 1815,3 & 1703,4 & 1890,4 \\
\hline
\end{tabular}

Fonte: Infoadex.

A pesar do descenso nos ingresos publicitarios obtidos entre 2012 e 2013, non sucedeu o mesmo para o número de anuncios emitidos, que aumentarán (cfr. Anuario SGAE das Artes Escénicas, Musicais e Audiovisuais 2014).

Atendendo aos xéneros da programación emitida polas emisoras públicas, observaremos que se mantén a mesma tendencia que se advirte no panorama nacional: a ficción é o xénero que ocupa máis tempo de emisión (Barlovento 
Comunicación 2014), se ben os datos relativos ás autonómicas reflicten unha maior presenza da información (no caso da TVG ocupa o segundo posto) (cfr. táboa 8). Algo ben diferente se observa no caso da TVG2, na que destacan os espazos que se catalogan como miscelánea ou musicais (un dato que sorprende en comparación coas autonómicas ou nacionais).

Táboa 8. Distribución do tempo de emisión das canles públicas galegas por xéneros (2013)

\begin{tabular}{lrr} 
Xéneros & TVG & TVG2 \\
\hline Relixioso & $1,0 \%$ & $0,0 \%$ \\
\hline Cultural & $14,4 \%$ & $8,4 \%$ \\
\hline Información & $\mathbf{2 3 , 5} \%$ & $18,6 \%$ \\
\hline Miscelánea & $19,6 \%$ & $\mathbf{4 0 , 7} \%$ \\
\hline Infoshow & $1,0 \%$ & $0,0 \%$ \\
\hline Concurso & $3,7 \%$ & $0,0 \%$ \\
\hline Deporte & $0,1 \%$ & $16,9 \%$ \\
\hline Toros & $0,0 \%$ & $0,0 \%$ \\
\hline Musical & $11,3 \%$ & $\mathbf{3 0 , 0} \%$ \\
\hline Ficción & $\mathbf{2 5 , 5} \%$ & $15,0 \%$ \\
\hline Programas venda & $0,0 \%$ & $0,0 \%$ \\
\hline Outros & $0,0 \%$ & $0,0 \%$ \\
\hline
\end{tabular}

Fonte: Anuario SGAE das Artes Escénicas, Musicais e Audiovisuais 2014.

\section{USO DA LINGUA GALEGA}

En canto ao uso do galego, observamos que nas públicas si se mantén o seu emprego en todos os programas (mediante un uso directo por parte dos presentadores ou intérpretes, así como mediante un proceso de dobraxe da ficción), salvo por parte dalgún invitado nos programas de produción galega. Desta forma, respéctase o artigo 6 da Lei 9/1984, do 11 de xullo, de creación da Compañía de Radio-Televisión de Galicia, na que se recolle que entre os principios que han de inspirar a programación dos medios xestionados pola Comunidade Autónoma de Galicia se atopa «[...] a promoción e difusión da Cultura e Lingua Galega, así como a defensa da identidade da nacionalidade galega». Esta indicación correspóndese co artigo 4, «Principios inspiradores e alcance», da Lei 9/2011, do 9 de novembro, dos medios públicos de comunicación audiovisual de Galicia, onde tamén se especifica que «a prestación do servizo de comunicación audiovisual por parte da devandita sociedade e as comunicacións que efectúe ao persoal dependente dela no exercicio das súas tarefas será en lingua galega», se ben non se especifica que debe facerse uso da forma do galego normativa e estándar. Neste senso, resulta significativo lembrar que durante este período se produciu unha situación que xerou debate cando a presentadora de A Revista no ano 2012, Lorena Pose, comezou a empregar para a presentación do programa a forma do galego con gheada -que previamente xa fora empregada na produción seriada de ficción Mareas Vivas (Antón Reixa, 1998-2002). Se ben a RAG admite a gheada como oficial, dende a dirección de informativos procedeuse a solicitar que se deixase de empregar esta forma do galego indicando que moita xente non se identificaba con esa variante e o seu uso nos informativos podería influír na credibilidade da canle ${ }^{5}$.

5 «TVG pide a una presentadora que no utilice la gheada» (24/03/2012), en El País na súa edición online http://ccaa.elpais.com/ ccaa/2012/03/24/galicia/1332614868_924474.html (25/03/2015). 
Por outra banda, de acordo co Informe de Servizo Público do grupo CRTVG para o ano 2013, incorpórase unha epígrafe relativa á normalización lingüística, na que se indica que se conta cun equipo de lingüistas orientado a conseguir unha maior calidade no uso da lingua.

No que atinxe á emisora privada, $\vee$ Televisión, podemos advertir que inclúe algúns contidos en español e outros en galego. Polo que podemos observar na información da súa páxina web corporativa (http://www.vtelevision.es), actualmente a gran maioría dos programas en emisión empregan o castelán para a súa realización. Daqueles espazos en emisión, a excepción son De bares (emprego do galego e castelán indistintamente) e Soño con Ciencia ou Ata a cociña! (realizados en galego).

\section{TENDENCIAS PARA O FUTURO}

A pesar da incerteza e dos cambios constantes aos que se está enfrontando o sector televisivo, semella que o futuro se achega con matices positivos, tal e como se amosa cos datos relativos ao investimento publicitario e polos propios datos de consumo (aos que nos debemos achegar non só dende o consumo propiamente televisivo, senón dende o punto de vista de consumo audiovisual, que se está vendo incrementado no público máis novo a través das segundas e terceiras pantallas).

Neste contexto de cambio e de transformación do comportamento do espectador no consumo audiovisual, as emisoras autonómicas, tanto as públicas como as privadas, é necesario que continúen transformándose e avanzando cara á contorna dixital. As actuacións deben formularse: en primeiro lugar, ofertando novas formas de consumir os seus contidos centradas no «anytime, anywhere», xa que o protagonista no presente e futuro inmediato será o espectador/consumidor; en segundo lugar, centrando a atención nos contidos, que deben estar creados para resultar atraentes na oferta a través da pantalla do televisor e con posibilidades de visionado online (tanto en directo como en diferido) e contemplando innovadoras posibilidades de investimento publicitario; e, en terceiro lugar, deben integrarse de forma estratéxica nas redes sociais e tratar de empregar fórmulas de participación e interacción con este novo espectador máis activo.

Con todo, observamos unha cuarta proposta de actuación estratéxica en relación coa principal preocupación que deben posuír as emisoras autonómicas públicas e que reside no cuestionamento que se está facendo nos últimos anos sobre o seu papel na sociedade. Para isto é preciso levar a cabo un proceso explicativo e de concienciación da súa función de servizo público que debe ficar clara dende a formulación dos seus contidos programáticos, diferenciais do resto de emisoras comerciais, e incentivando a promoción dos elementos culturais, lingüísticos e identitarios da comunidade galega. 


\section{REFERENCIAS BIBLIOGRÁFICAS}

AIMC (2014): Marco Xeral dos Medios de Comunicación 2014.

BaRlovento Comunicación (2014): Análisis televisivo 2014. Consulta realizada o 22/03/2015 en http://www. barloventocomunicación.es.

BARLovento Comunicación (2013): Análisis televisivo 2013. Consulta realizada o 22/03/2015 en http://www.barloventocomunicación.es.

BARLovento Comunicación (2012): Análisis televisivo 2012. Consulta realizada o 22/03/2015 en http://www.barloventocomunicación.es.

EGEDA (2013): Panorama Audiovisual 2012, Madrid, Entidad de Gestión de los Derechos de los Productores Audiovisuales.

FAndiÑo, X. / A. DAFonte (2007): «A televisión en Galicia: actualidade e futuro», en X. López García (coord.), A comunicación en Galicia 2007, Santiago de Compostela, Consello da Cultura Galega.

INFOADEX (2015): Estudio Infoadex de la inversión publicitaria en España 2014. Resumen. Consulta realizada o 25/03/2015 en http://www.infoadex.es.

INFOADEX (2014): Estudio Infoadex de la inversión publicitaria en España 2013. Resumen. Consulta realizada o 25/03/2015 en http://www.infoadex.es.

IINFOADEX (2013): Estudio Infoadex de la inversión publicitaria en España 2012. Resumen. Consulta realizada o 25/03/2015 en http://www.infoadex.es.

INFOADEX (2012): Estudio Infoadex de la inversión publicitaria en España 2011. Resumen. Consulta realizada o 25/03/2015 en http://www.infoadex.es.

Kantar Media España: Boletíns mensuais de estudos das audiencias. Consulta realizada o 20/02/2015 en www.kantarmedia.es. SGAE (2015): Anuario SGAE das Artes Escénicas, Musicais e Audiovisuais 2014. Consulta realizada o 05/03/2015 en http:// www.anuariossgae.com/anuario2014/anuariopdfs/07_TV.pdf.

ZENITH (2014): Los medios en España y Portugal 2014, Madrid, Zenith.

ZENITH (2013): Los medios en España y Portugal 2013, Madrid, Zenith. 